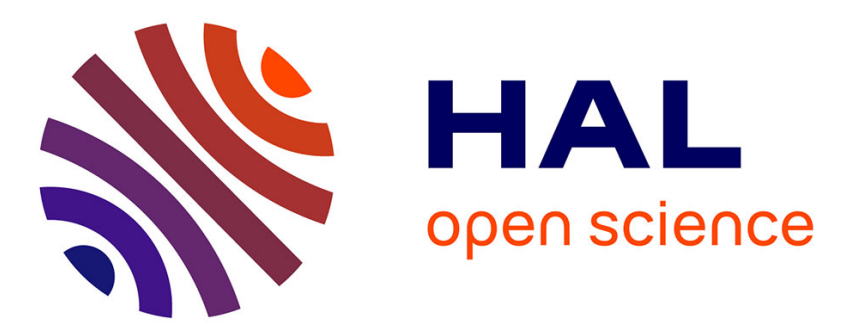

\title{
Concentration-Gradient Prussian Blue Cathodes for Na-Ion Batteries
}

$\mathrm{Pu} \mathrm{Hu}$, Wenbo Peng, Bo Wang, Dongdong Xiao, Utkarsh Ahuja, Julien

Réthoré, Katerina Aifantis

\section{To cite this version:}

$\mathrm{Pu} \mathrm{Hu}$, Wenbo Peng, Bo Wang, Dongdong Xiao, Utkarsh Ahuja, et al.. Concentration-Gradient Prussian Blue Cathodes for Na-Ion Batteries. ACS Energy Letters, 2019, 5 (1), pp.100-108. 10.1021/acsenergylett.9b02410 . hal-02436261

\section{HAL Id: hal-02436261 \\ https://hal.science/hal-02436261}

Submitted on 18 Nov 2020

HAL is a multi-disciplinary open access archive for the deposit and dissemination of scientific research documents, whether they are published or not. The documents may come from teaching and research institutions in France or abroad, or from public or private research centers.
L'archive ouverte pluridisciplinaire HAL, est destinée au dépôt et à la diffusion de documents scientifiques de niveau recherche, publiés ou non, émanant des établissements d'enseignement et de recherche français ou étrangers, des laboratoires publics ou privés.

\section{(c)(1)}

Distributed under a Creative Commons Attribution| 4.0 International License 


\section{Concentration-gradient Prussian blue cathodes for}

\section{Na-ion batteries}

Pu Hu, ${ }^{\dagger}$ Wenbo Peng, ${ }^{\dagger}$ Bo Wang,,$^{\dagger}$ Dongdong Xiao, ${ }^{\perp}$ Utkarsh Ahuja, $\dagger$ Julien Réthoré,,$\$$ and Katerina E. Aifantis, ${ }^{* \dagger}$

${ }^{\dagger}$ Department of Mechanical and Aerospace Engineering, University of Florida, Gainesville, 32603, USA

${ }^{\perp}$ Beijing National Laboratory for Condensed Matter Physics, Institute of Physics, Chinese Academy of Sciences, Beijing 100190, China

${ }^{\S}$ Research Institute in Civil and Mechanical Engineering (Gem), CNRS UMR 6183 CNRS / Ecole Centrale de Nantes / Université de Nantes, F-44 321, Nantes, France.

\section{AUTHOR INFORMATION}

\section{Corresponding Author}

*Email: kaifantis@ufl.edu

ABSTRACT A concentration-gradient composition is proposed as an effective approach to solve the mechanical degradation and improve the electrochemical cyclability for cathodes of sodiumion batteries. Concentration-gradient shell $\mathrm{Na}_{x} \mathrm{Ni}_{y} \mathrm{Mn}_{1-y} \mathrm{Fe}(\mathrm{CN})_{6} \cdot n \mathrm{H}_{2} \mathrm{O}$, in which the Ni content gradually increases from the interior to the particle surface, is synthesized by a facile co- 
precipitation process. The as-obtained cathode exhibits an improved electrochemical performance compared to homogeneous $\mathrm{Na}_{x} \mathrm{MnFe}(\mathrm{CN})_{6} \cdot n \mathrm{H}_{2} \mathrm{O}$, delivering a high reversible specific capacity of $110 \mathrm{~mA} \mathrm{~h} \mathrm{~g}^{-1}$ at $0.2 \mathrm{C}$ and outstanding cycling stability ( $93 \%$ retention after 1000 cycles at $5 \mathrm{C}$ ). The improvement of electrochemical performance can be attributed to its robust microstructure that effectively alleviates the electrochemically induced stresses and accumulated damage during sodiation/desodiation and thus prevents the initiation of fracture in the particles upon long term cycling. These findings render a prospective strategy to develop high-performance electrode materials for sodium-ion batteries.

\section{TOC GRAPHICS}

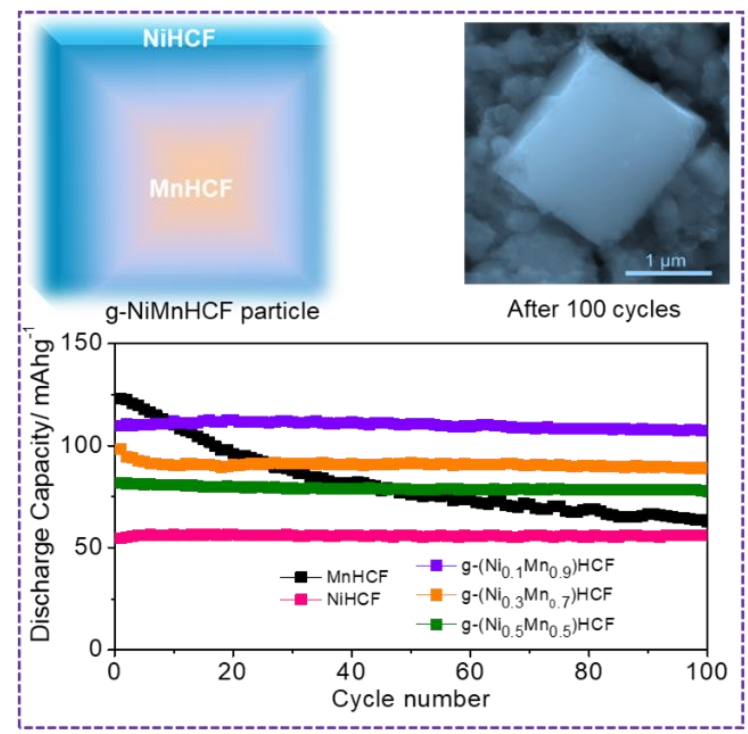

Sodium ion batteries (SIBs) have been gaining increased attention as a potential energy storage device. ${ }^{1-4}$ Compared to lithium, sodium is available abundantly and relatively inexpensive, thereby reducing the cost of the electrode material. Moreover, sodium has similar electrochemical properties to lithium and maintains a good reversibility in a variety of host materials. Hence, 
significant efforts are being undertaken to commercialize SIBs for large-scale energy storage (EES) systems. Recently, a SIBs system with a power rating of $30 \mathrm{~kW} / 100 \mathrm{kWh}$ was installed in China. ${ }^{5}$ Nevertheless, long-term cycling stability of SIBs still remains a challenge.

Mechanical degradation is commonly observed in both cathode and anode materials of Li-ion batteries, which is the leading contributor of capacity decay of batteries. ${ }^{6-10}$ Fracture of the electrodes is caused by volume expansions, phase transformations, formation of oxygen vacancies and surface corrosion of the active materials upon intercalation. ${ }^{11-14}$ Such mechanisms have been experimentally observed in cathode materials $\left(\mathrm{LiNi}_{1 / 3} \mathrm{Mn}_{1 / 3} \mathrm{Co}_{1 / 3} \mathrm{O}_{2}, \mathrm{LiMn}_{2} \mathrm{O}_{4}, \mathrm{LiFePO}_{4}\right)$ for LIBs, ${ }^{14-16}$, and although their volumetric expansions are less than $10 \%(2.0 \%$ expansion along c direction for $\mathrm{LiNi}_{1 / 3} \mathrm{Mn}_{1 / 3} \mathrm{Co}_{1 / 3} \mathrm{O}_{2}{ }^{17}, 7 \%$ expansion for $\mathrm{LiFePO}_{4}{ }^{18}$, and $6.77 \%$ expansion for $\mathrm{LiFePO}{ }_{4}{ }^{19}$ ), repeated lattice expansion and contraction during electrochemical cycling leads to accumulation of damage which subsequently leads to mechanical degradation of the electrode. Due to the larger ionic radius of $\mathrm{Na}^{+}$from $\mathrm{Li}^{+}$, the electrode during sodiation/desodiation is subjected to larger volumetric strains and more complicated multi-phase transformations than those during lithiation/delithiation. ${ }^{20-21}$ This suggests that mechanical degradation may result in more severe damage in cathode materials during the charge/discharge process in SIBs. Our previous research revealed that the maximum effective von Mises stress in a layered-type $\mathrm{TiS}_{2}$ cathode was four times higher during sodiation than lithiation and numerous cracks were observed with electron microscopy after continuous electrochemical cycling. Therefore, understanding the mechanical degradation as well as (de)sodiation-induced fracture of cathodes is essential in achieving long-term stability in SIBs. To date, a systematic investigation on the effect of the cathode mechanical properties to the electrochemical performance of SIBs is lacking. 
Prussian blue and its analogues (PBAs) with a unique 3D open-framework are promising cathode materials for SIBs. ${ }^{22-24}$ These materials have a general formula of $\mathrm{A}_{\mathrm{x}} \mathrm{M}_{\mathrm{y}} \mathrm{Fe}(\mathrm{CN})_{6} \cdot \mathrm{nH}_{2} \mathrm{O}$, abbreviated as MHCF, ( $\mathrm{A}$ is the alkali cation and $\mathrm{M}$ is a divalent or trivalent transition metal), in which six-fold C-coordinated Fe and six-fold N-coordinated M are connected by $\mathrm{CN}$ ligands, forming $\mathrm{Fe}-\mathrm{C} \equiv \mathrm{N}-\mathrm{M}$ linked open-frameworks and large interstitial sites. The wide channels and weak interaction between the $\mathrm{Na}^{+}$ion and the cyanide triple bonds in such a unique structure allows fast $\mathrm{Na}^{+}$diffusion. Among PBAs, $\mathrm{Na}_{x} \mathrm{MnFe}(\mathrm{CN})_{6}$ (MnHCF) exhibits a high redox potential and high theoretical capacity of $171 \mathrm{mAh} / \mathrm{g}$, which is comparable to commercial $\mathrm{LiFePO}_{4}$ cathodes in LIBs. ${ }^{25-28}$ However, a capacity decay is observed experimentally, as previous reports ${ }^{29-31}$ show that only a $30 \%$ capacity retention is achieved after 200 cycles at $0.5 \mathrm{C}$ in liquid electrolyte, which has been attributed to structural instabilities that take place during electrochemical cycling. Participation of both $\mathrm{Fe}$ and $\mathrm{Mn}$ sites in redox reactions results in lattice distortion and changes the $\mathrm{C} \equiv \mathrm{N}$ bond length. Moreover, the structural instability of MnHCF is also caused by the crystal Jahn-Teller (J-T) distortion of $\mathrm{Mn}^{3+}\left(\mathrm{t}_{2 \mathrm{~g}}{ }^{3} \mathrm{e}_{\mathrm{g}}{ }^{1}\right)^{32}$ and volume changes $(\sim 8.5 \%)^{31}$ during cycling. In addition to structural changes, dissolution of Mn species in the organic electrolyte leads to surface corrosion of the electrode..$^{29}$ All these factors would be expected to contribute to local fracture and mechanical degradation of the PBA electrode, leading to capacity decay. It is known that $\mathrm{Ni}^{2+}$ is electrochemically inert in $\mathrm{Na}_{2} \mathrm{NiFe}(\mathrm{CN})_{6}(\mathrm{NiHCF})$ and $\mathrm{Fe}$ is the only redox active site, making the $\mathrm{Fe}-\mathrm{C} \equiv \mathrm{N}-\mathrm{Ni}$ bond extremely stable. Earlier studies have shown that NiHCF undergoes zero lattice strain (volume change $\sim 0.29 \%$ ) during sodiation/desodiation and displays excellent cycling stability (90\% capacity retention over 1000 cycles). ${ }^{27}$

In the present study a concentration-gradient composition is proposed as an effective approach to solve the mechanical degradation and improve the electrochemical cyclability for 
cathodes of sodium-ion batteries. Concentration-gradient $\mathrm{Na}_{x} \mathrm{Ni}_{y} \mathrm{Mn}_{1-y} \mathrm{Fe}(\mathrm{CN})_{6} \cdot n \mathrm{H}_{2} \mathrm{O} \quad(\mathrm{g}$ $\left.\mathrm{Na}_{x} \mathrm{Ni}_{y} \mathrm{Mn}_{1-y} \mathrm{Fe}(\mathrm{CN})_{6} \cdot n \mathrm{H}_{2} \mathrm{O}\right)$, in which $\mathrm{Ni}$ gradually increases while Mn decreases from the interior to the particle surface, is synthesized by a facile co-precipitation process. The NiHCF shell does not experience volume changes upon sodiation and was anticipated to increase the mechanical stability of the MnHCF rich core that undergoes volume changes upon cycling. Phase field modelling is employed to capture the internal stresses developed during cycling and correlate mechanical with electrochemical stability. In addition to testing the performance of these PBA materials in a half cell, a full cell was also fabricated and tested using either graphite or $\mathrm{TiS}_{2}$ as the anode. 


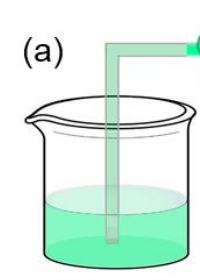

(A)

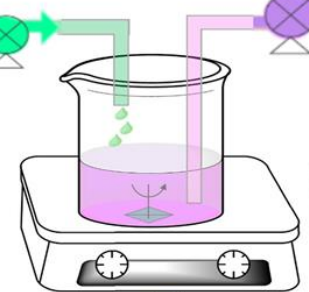

(B)

$\mathrm{MnCl}_{2}$ solution
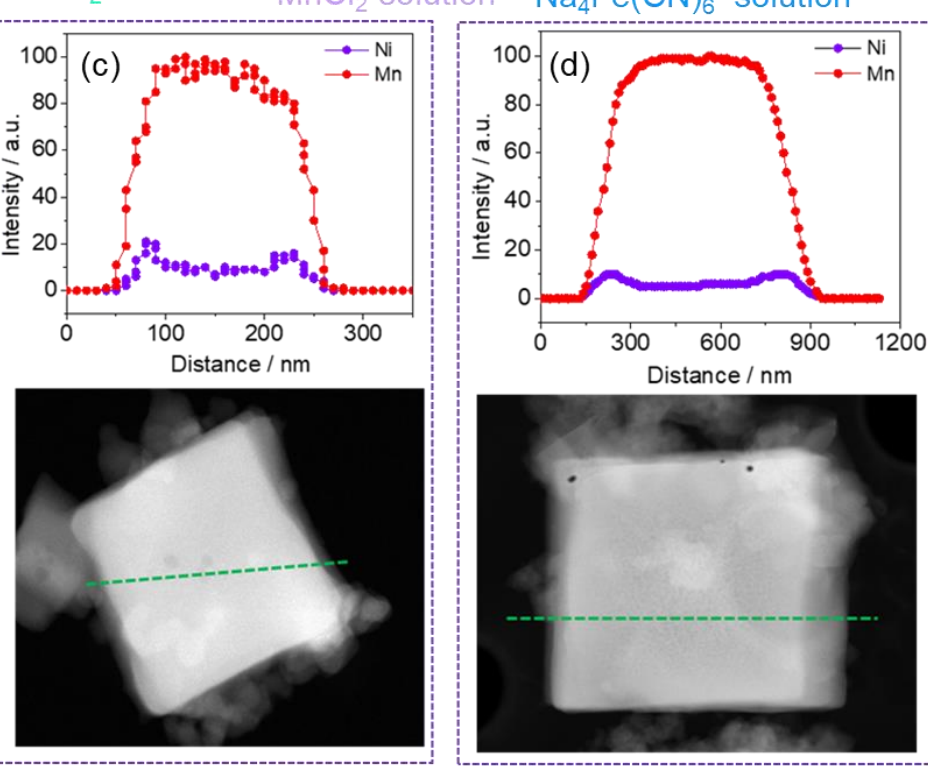

(c)
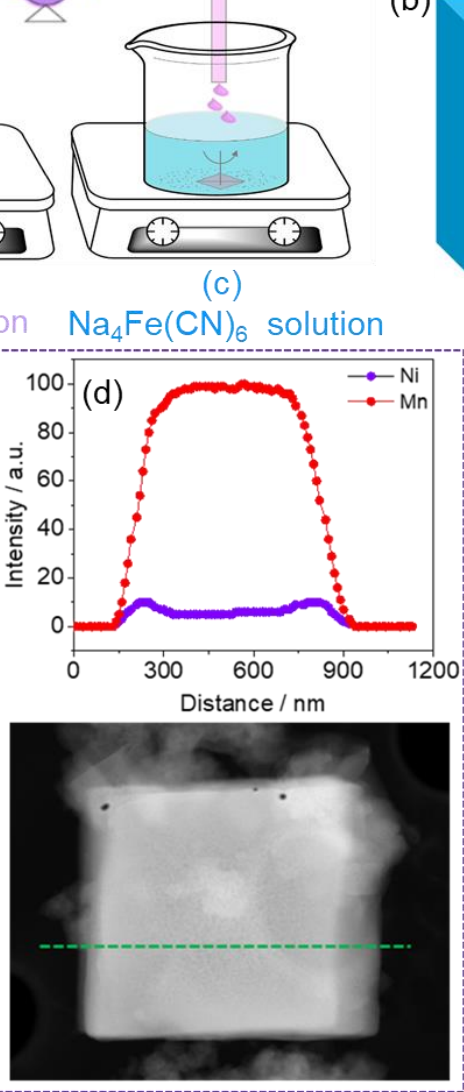

(b)

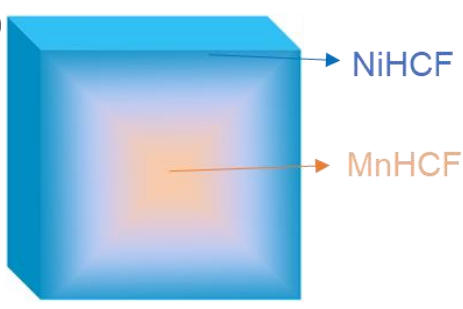

g-NiMnHCF particle
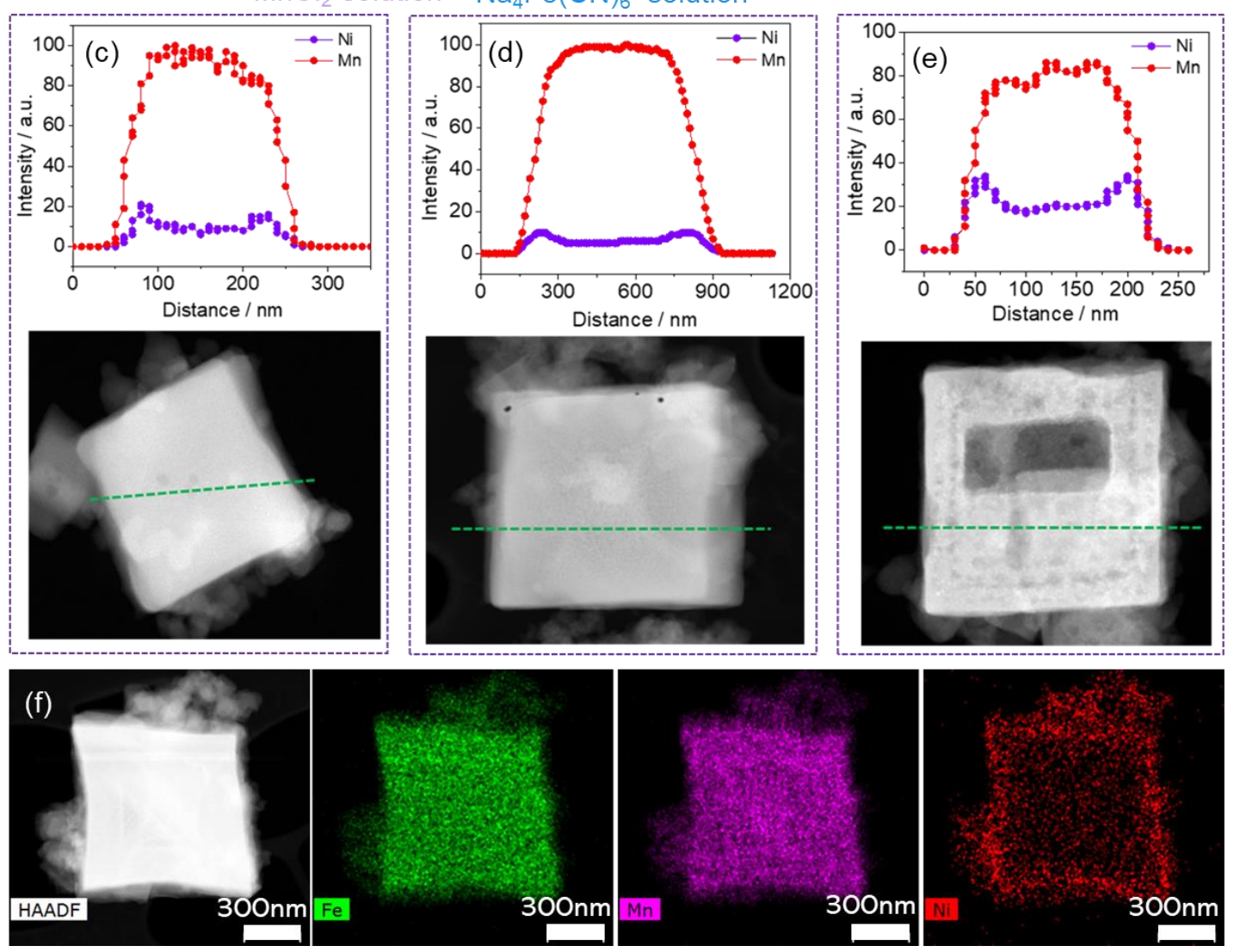

Figure 1 (a) Schematics illustrating the preparation of g-NiMnHCF. (b) Illustration of a gradient particle, where NiHCF gradually increases while MnHCF decreases from the interior to the particle surface, forming a core/shell structure. (c)-(e) STEM images and EDX linear scan for the typical gradient particles with different $\mathrm{Ni} / \mathrm{Mn}$ ratios: (c) g-( $\left.\mathrm{Ni}_{0.1} \mathrm{Mn}_{0.9}\right) \mathrm{HCF}$, (d) g$\left(\mathrm{Ni}_{0.3} \mathrm{Mn}_{0.7}\right) \mathrm{HCF}$ and (e) g-(Ni $\left.\mathrm{Ni}_{0.5} \mathrm{Mn}_{0.5}\right) \mathrm{HCF}$. (f) STEM images and element mapping for g$\left(\mathrm{Ni}_{0.3} \mathrm{Mn}_{0.7}\right) \mathrm{HCF}$. 
Concentration-gradient particles of g-(NiMn)HCF were prepared via a scalable coprecipitation process, as described in Figure 1a. $\mathrm{Ni}^{2+}$ solution was slowly pumped into the $\mathrm{Mn}^{2+}$ to obtain a mixture with increasing $\mathrm{Ni}^{2+}$ concentration. The resultant mixture of $\mathrm{Ni}^{2+} / \mathrm{Mn}^{2+}$ was precisely pumped into $\mathrm{Na}_{4} \mathrm{Fe}(\mathrm{CN})_{6}$ solution to form a precipitate under constant magnetic stirring. As a result, concentration-gradient particles with a Ni-rich surface and Mn-rich core were obtained (Figure1b). By adjusting the molar ratio of $\mathrm{Ni}^{2+}$ and $\mathrm{Mn}^{2+}(1: 9,3: 7,1: 1)$, a series of gradient $\mathrm{Na}_{x}\left(\mathrm{Ni}_{\mathrm{y}} \mathrm{Mn}_{\mathrm{z}}\right) \mathrm{HCF}$ with different stoichiometries were synthesized. Thermogravimetric analysis (TGA) (Figure S1) and ICP-OES (Table.S1) were carried out to determine the composition of the obtained materials, which were identified as $\mathrm{Na}_{1.17}\left(\mathrm{Ni}_{0.12} \mathrm{Mn}_{0.88}\right)\left[\mathrm{Fe}(\mathrm{CN})_{6}\right]_{0.79} \cdot 1.5 \mathrm{H}_{2} \mathrm{O}$, $\mathrm{Na}_{1.37}\left(\mathrm{Ni}_{0.28} \mathrm{Mn}_{0.72}\right)\left[\mathrm{Fe}(\mathrm{CN})_{6}\right]_{0.84} \cdot 2.39 \mathrm{H}_{2} \mathrm{O}$ and $\mathrm{Na}_{1.81}\left(\mathrm{Ni}_{0.59} \mathrm{Mn}_{0.41}\right)\left[\mathrm{Fe}(\mathrm{CN})_{6}\right]_{0.95} \cdot 3.3 \mathrm{H}_{2} \mathrm{O}$. The molar ratio of Ni/Mn in these materials was found to be close to the molar ratio of $\mathrm{Ni}^{2+} / \mathrm{Mn}^{2+}$ mixture used in the synthesis. We denoted them as $\mathrm{g}-\left(\mathrm{Ni}_{0.1} \mathrm{Mn}_{0.9}\right) \mathrm{HCF}, \mathrm{g}-\left(\mathrm{Ni}_{0.3} \mathrm{Mn}_{0.7}\right) \mathrm{HCF}$ and $\mathrm{g}-$ $\left(\mathrm{Ni}_{0.5} \mathrm{Mn}_{0.5}\right) \mathrm{HCF}$. Figure $\mathrm{S} 2$ shows the X-ray diffraction (XRD) patterns of the gradient materials as well as the homogeneous MnHCF and NiHCF. The splitting diffraction peaks for MnHCF at around $23.7^{\circ}$ and $37.9^{\circ}$ are a notable characteristic of monoclinic phases $\left(\mathrm{P} 2{ }_{1} / \mathrm{n}\right.$ space group). From MnHCF to NiHCF, the diffraction peak shifted to a higher angle with increasing the Ni content in the materials. This is due to the radius of $\mathrm{Ni}^{2+}(0.69 \AA)$ being smaller than that of $\mathrm{Mn}^{2+}(0.83 \AA)$, leading to the shrinkage of the lattice for compounds with higher Ni contents. Fourier-transform infrared spectroscopy (FTIR) was performed to probe the chemical structure of the obtained materials. The absorption peak at $2085 \mathrm{~cm}^{-1}$ in FTIR (Figure S3) revealed the characteristic stretching vibration of the cyanide $(\mathrm{Fe}-\mathrm{C} \equiv \mathrm{N}-\mathrm{M}, \mathrm{M}=\mathrm{Mn}, \mathrm{Ni})$ group. Since the electronegativity of $\mathrm{Ni}$ (1.91) is higher than $\mathrm{Mn}$ (1.55), the substitution of $\mathrm{Ni}$ with Mn could induce an inductive effect, 
which lead to the blue shift of the peak. With increasing the Ni concentration, the absorption peak gradually shifted to a higher wavenumber.

Scanning transmission electron microscopy (STEM) was carried out to determine the local composition and distribution of transition metals within a single particle. All the particles displayed a typical cubic nanostructure. Figure 1c-e shows the EDS (electron diffraction spectroscopy) line scan and the corresponding STEM images of g-( $\left.\mathrm{Ni}_{0.1} \mathrm{Mn}_{0.9}\right) \mathrm{HCF}$ (Figure1c), g$\left(\mathrm{Ni}_{0.3} \mathrm{Mn}_{0.7}\right) \mathrm{HCF}$ (Figure1d) and g-(Ni $\left.\mathrm{Ni}_{0.5} \mathrm{Mn}_{0.5}\right) \mathrm{HCF}$ (Figure 1e) particles. The results reveal that all samples display the similar trend of distribution of $\mathrm{Ni}$ and $\mathrm{Mn}$ in the particle, where the $\mathrm{Ni}$ concentration increases gradually from the center towards the surface, and the Mn concentration is low on the surface but increases near the center of the particle. The gradient distribution of the transition metal in the particle is further confirmed by EDS element mapping (Figure 1f, Figure S4). Compared with the homogeneous distribution of Fe, the Ni and Mn are heterogeneously distributed between the center and surface. However, the intensity ratio of $\mathrm{Ni} / \mathrm{Mn}$ is different from the designed ratio and the ICP-OES results. It might be due to the different solubility between MnHCF $\left(\mathrm{K}_{\mathrm{sp}} \sim 10^{-3}\right)$ and NiHCF $\left(\mathrm{K}_{\mathrm{sp}} \sim 10^{-16}\right)$, leading to the formation of NiHCF particles that mixed with the gradient materials. As shown in Figure S5, g-( $\left.\mathrm{Ni}_{0.1} \mathrm{Mn}_{0.9}\right) \mathrm{HCF}$ comprises of microcubes of similar sizes. STEM images and the corresponding linear scan results of homogeneous $\left(\mathrm{Ni}_{0.1} \mathrm{Mn}_{0.9}\right) \mathrm{HCF}$ and $\left(\mathrm{Ni}_{0.3} \mathrm{Mn}_{0.7}\right) \mathrm{HCF}$ samples are shown in Figure S6, in which $\mathrm{Ni}, \mathrm{Fe}$ and Mn elements exhibit a flat intensity along the linear scan, indicating the homogenous distribution of element from inner to the surface. These observations confirm that the synthesis method employed here can be applied to a wide range of Ni:Mn compounds to form a gradient particle with a controllable composition. 
Figure 2 compares the electrochemical performance of gradient composites with different Ni:Mn ratios and the homogeneous phase of MnHCF and NiHCF in Na half-cells. Figure 2a shows the initial galvanostatic charge/discharge voltage profile of cycled cells at $0.2 \mathrm{C}$. NiHCF displays a voltage plateau at $\sim 3.4 \mathrm{~V}$ during charge and $\sim 3.2 \mathrm{~V}$ during discharge, which is associated with the redox reaction of $\mathrm{Fe}^{2+/ 3+}-\mathrm{C} \equiv \mathrm{N}-\mathrm{Ni}$. The initial charge and discharge capacities of NiHCF are $55 \mathrm{mAh} / \mathrm{g}$ and $60 \mathrm{mAh} / \mathrm{g}$, respectively. Although the capacity exhibited by NiHCF is lower when compared with gradient materials and $\mathrm{MnHCF}$, NiHCF retains nearly $100 \%$ of its capacity after 100 cycles at $0.2 \mathrm{C}$ (Figure 2b), displaying superior cycling stability. For the MnHCF cathode, two plateaus are observed (Figure 2a): the voltage plateau at 3.4V $/ 3.2 \mathrm{~V}$ for charge / discharge shows similar redox reactions as seen in $\mathrm{NiHCF}$, and are attributed to the redox pair of $\mathrm{Fe}^{2+/ 3+}-\mathrm{C} \equiv \mathrm{N}-\mathrm{Mn}$. In addition, a higher voltage plateau at 3.7V / 3.5 V (Figure S7) for charge / discharge is related to the redox reaction of $\mathrm{Fe}-\mathrm{C} \equiv \mathrm{N}-\mathrm{Mn}^{2+/ 3+}$. Figure $\mathrm{S} 8$ shows the charge/discharge (Figure S8a) and differential capacities versus voltage (dQ/dv) curves (Figure $\mathrm{S} 8 \mathrm{~b})$ of MnHCF cathodes during cycling. Structural reconstruction characteristics of loss of interstitial water from crystal structure causes the higher voltage plateau to decrease by $0.2 \mathrm{~V}$ over initial cycling.

Owing to two active redox sites of $\mathrm{Fe}^{2+/ 3+}$ and $\mathrm{Mn}^{2+/ 3+}$ in $\mathrm{Fe}-\mathrm{C} \equiv \mathrm{N}-\mathrm{Mn}$, MnHCF exhibits the highest reversible capacity, however, its capacity retention is poor. As shown in Figure 2b, the discharge capacity of MnHCF decreases rapidly from $122 \mathrm{mAh} / \mathrm{g}$ to $64 \mathrm{mAh} / \mathrm{g}$, corresponding to a capacity retention of a meagre $52.5 \%$ after 100 cycles. The voltage plateaus become shorter and a larger overpotential is observed upon cycling. These inferior electrochemical properties of $\mathrm{MnHCF}$ in liquid electrolytes are consistent with previous reports. ${ }^{29}$ 

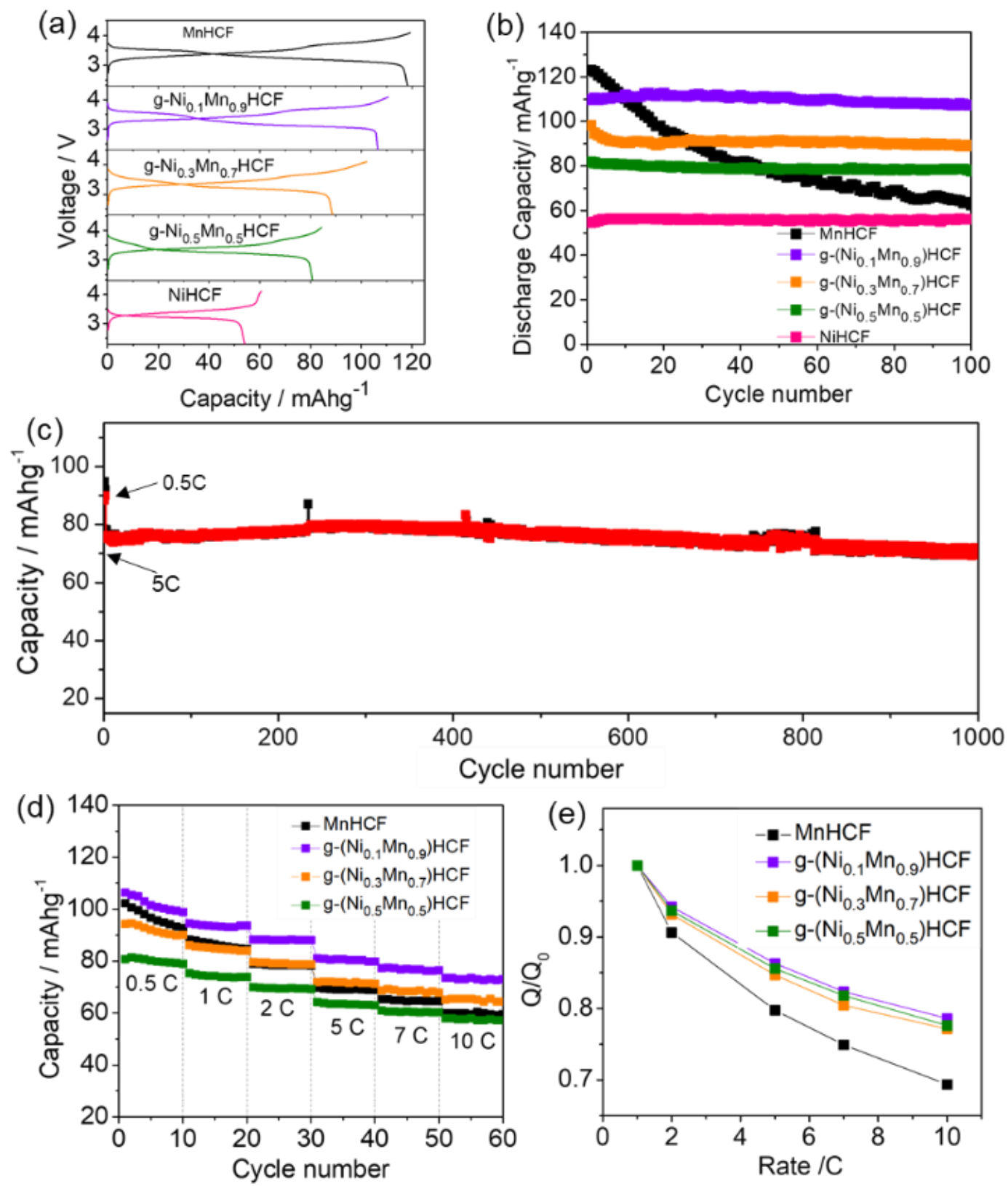

Figure 2 (a) Charge/discharge curves and (b) cycling performance of gradient material, MnHCF and NiHCF at $0.2 \mathrm{C}$; (c) long-term cycling of the typical g-( $\left.\mathrm{Ni}_{0.3} \mathrm{Mn}_{0.7}\right) \mathrm{HCF}$ at $5 \mathrm{C}$; (d) rate capability and (e) normalized capacity of gradient materials at different C-rates.

Different Ni:Mn ratios in the concentration-gradient cathodes, bring about changes in the reversible capacity and the voltage plateau. The voltage profiles (Figure $2 \mathrm{a})$ of $\mathrm{g}-\left(\mathrm{Ni}_{0.5} \mathrm{Mn}_{0.5}\right) \mathrm{HCF}$, g-( $\left.\mathrm{Ni}_{0.3} \mathrm{Mn}_{0.7}\right) \mathrm{HCF}$ and $\mathrm{g}-\left(\mathrm{Ni}_{0.1} \mathrm{Mn}_{0.9}\right) \mathrm{HCF}$ reveal two plateaus at 3.4V/3.2 $\mathrm{V}$ and $3.7 \mathrm{~V} / 3.5 \mathrm{~V}$ when 
cycled between 2.0-4.1 V. The presence of the $3.2 \mathrm{~V}$ plateau is indicative of the $\mathrm{Fe}^{2+/ 3+}$ redox couple which delivers a similar capacity to the homogenous MnHCF and NiHCF, whereas the high voltage plateau $(3.5 \mathrm{~V} / 3.7 \mathrm{~V})$ associated with the redox couple of $\mathrm{Mn}^{2+/ 3+}$ becomes longer with the reduction of $\mathrm{Ni}$ in the particle. The reversible capacities (Figure $2 \mathrm{~b}$ ) of g-( $\left.\mathrm{Ni}_{0.1} \mathrm{Mn}_{0.9}\right) \mathrm{HCF}, \mathrm{g}-$ $\left(\mathrm{Ni}_{0.3} \mathrm{Mn}_{0.7}\right) \mathrm{HCF}$ and g-(Ni $\left.\mathrm{Ni}_{0.5} \mathrm{Mn}_{0.5}\right) \mathrm{HCF}$ are $110 \mathrm{mAh} \mathrm{g}^{-1}, 98 \mathrm{mAh} \mathrm{g}^{-1}$ and $82 \mathrm{mAh} \mathrm{g}^{-1}$ at $0.2 \mathrm{C}$, respectively. It is seen that capacity decreased with the increasing Ni:Mn ratio and a lower Coulombic efficiency (C.E.) was seen in initial cycles, which might be attributed into the decomposition of electrolyte. The gradient-concentration materials showed a lower initial capacity than MnHCF, however, an improved cycling performance with a capacity retention of $95 \%, 93 \%$ and $96 \%$ after 100 cycles was observed, which is considerably higher than that of MnHCF (52.5\%). Such a trend was expected since $\mathrm{NiFCH}$ has a better stability, whereas MnHCF a higher capacity, however, the ability of just a small addition of $\mathrm{Ni}$ to increase the stability so drastically was not anticipated. As shown in Figure S9, in comparison with the gradient materials, the non-gradient materials $\left(\mathrm{Ni}_{0.1} \mathrm{Mn}_{0.9}\right) \mathrm{HCF}$ and $\left(\mathrm{Ni}_{0.3} \mathrm{Mn}_{0.7}\right) \mathrm{HCF}$ display capacity retentions of $86 \%$ and $84 \%$ after 100 cycles, respectively. The long-term cycling stability was evaluated by galvanostatic charge/discharge tests at $0.5 \mathrm{C}$ for the first-two cycles and then at $5 \mathrm{C}$ for 1000 cycles (Figure 2c). The g-( $\left.\mathrm{Ni}_{0.3} \mathrm{Mn}_{0.7}\right) \mathrm{HCF}$ cathode delivered a high capacity retention of $93 \%$ after 1000 cycles (The capacity retention was calculated based on the value of $5 \mathrm{C}$ in Figure 2c). Comparing the XRD patterns for this cathode (Figure S10) from before and after cycling showed that no apparent changes occurred after 1000 cycles, in accordance with the stable long-term cycling performance of the gradient composite.

The rate capability of the obtained materials was evaluated at different current densities ranging from $0.5 \mathrm{C}$ to $10 \mathrm{C}$ in the voltage range of $2.0 \sim 4.1 \mathrm{~V}$ at room temperature. As shown in 
Figure 2d, the capacity of the MnHCF cathode decreased rapidly with increasing the current density from $100 \mathrm{mAh} / \mathrm{g}$ at $1 \mathrm{C}$ to $60 \mathrm{mAh} / \mathrm{g}$ at $10 \mathrm{C}$. In contrast, the g-NiMnHCF samples maintained most of their capacity and showed excellent rate capabilities in a wide range of current densities. The separation of the potential (Figure S11) between charge and discharge increased slightly with increasing the C-rate, implying the weak polarization and overpotential during the electrochemical process. A discharge capacity of $110 \mathrm{mAh} \mathrm{g}^{-1}$ and $100 \mathrm{mAh} \mathrm{g}^{-1}$ was observed for the g-( $\left(\mathrm{Ni}_{0.1} \mathrm{Mn}_{0.9}\right) \mathrm{HCF}$ cathode at $0.5 \mathrm{C}$ and $1 \mathrm{C}$, respectively, and decreased slightly with increasing the $\mathrm{C}$-rate. The electrode exhibited a high capacity of $72 \mathrm{mAh} \mathrm{g}^{-1}$ at $10 \mathrm{C}$, corresponding to a $78 \%$ capacity retention at $1 \mathrm{C}$. Although the $\mathrm{g}$ - $\left(\mathrm{Ni}_{0.5} \mathrm{Mn}_{0.5}\right) \mathrm{HCF}$ cathode delivered the lowest specific capacity at $0.5 \mathrm{C}$ due to the inactivity of $\mathrm{Ni}^{2+}$, it exhibited the least capacity decay with an increase in current density, indicating the excellent high-rate capability.

Figure $2 \mathrm{e}$ compares the normalized capacity $\left(\mathrm{Q}_{\mathrm{Q}} \mathrm{Q}_{0}\right)$ of the samples at different current densities. Q is the capacity at different $\mathrm{C}$-rates, and $\mathrm{Q}_{0}$ is the capacity of electrodes at $1 \mathrm{C}$. The normalized capacity of g-NiMnHCF was higher than that of the MnHCF cathode at current densities ranging from $2 \mathrm{C}$ to $10 \mathrm{C}$. The g-( $\left.\mathrm{Ni}_{0.5} \mathrm{Mn}_{0.5}\right) \mathrm{HCF}$ cathode retained $78 \%$ of its capacity when cycled at $10 \mathrm{C}$ against just the $67 \%$ retention MnHCF. This further supports the excellent electrochemical performance of gradient materials $\left(\mathrm{g}-\left(\mathrm{Ni}_{0.1} \mathrm{Mn}_{0.9}\right) \mathrm{HCF}, \mathrm{g}-\left(\mathrm{Ni}_{0.3} \mathrm{Mn}_{0.7}\right) \mathrm{HCF}\right.$ and g$\left.\left(\mathrm{Ni}_{0.5} \mathrm{Mn}_{0.5}\right) \mathrm{HCF}\right)$ in terms of cycling stability and rate capability achieved, with minimal sacrifice of the specific capacity when compared with homogenous MnHCF. The high rate capability is determined by a fast ion diffusion and charge transfer in the electrode during the electrochemical process. The diffusion coefficient of $\mathrm{Na}^{+}\left(D_{\mathrm{Na}+}\right)$ in the cathode (g-( $\left.\mathrm{Ni}_{0.1} \mathrm{Mn}_{0.9}\right) \mathrm{HCF}$ and MnHCF) was estimated from cyclic voltammograms (CV) with varying scan speeds by the Randles-Sevcik method. ${ }^{33-34}$ As shown in Figure $\mathrm{S} 12$, the $D_{\mathrm{Na}}$ value in the g-( $\left.\mathrm{Ni}_{0.1} \mathrm{Mn}_{0.9}\right) \mathrm{HCF}$ cathode during 
sodiation and desodiation was $4.8 \times 10^{-11} \mathrm{~cm}^{2} \mathrm{~s}^{-1}$ and $5.9 \times 10^{-11} \mathrm{~cm}^{2} \mathrm{~s}^{-1}$, respectively, which is higher than $D_{\mathrm{Na}+}$ in the pure MnHCF cathode $\left(2.4 \times 10^{-11} \mathrm{~cm}^{2} \mathrm{~s}^{-1}\right.$ for sodiation and $3.8 \times 10^{-11} \mathrm{~cm}^{2} \mathrm{~s}^{-1}$ for desodiation). Therefore, the gradient substitution by $\mathrm{Ni}$ enhanced the $\mathrm{Na}^{+}$diffusivity in the electrode, resulting into the faster rate capability.
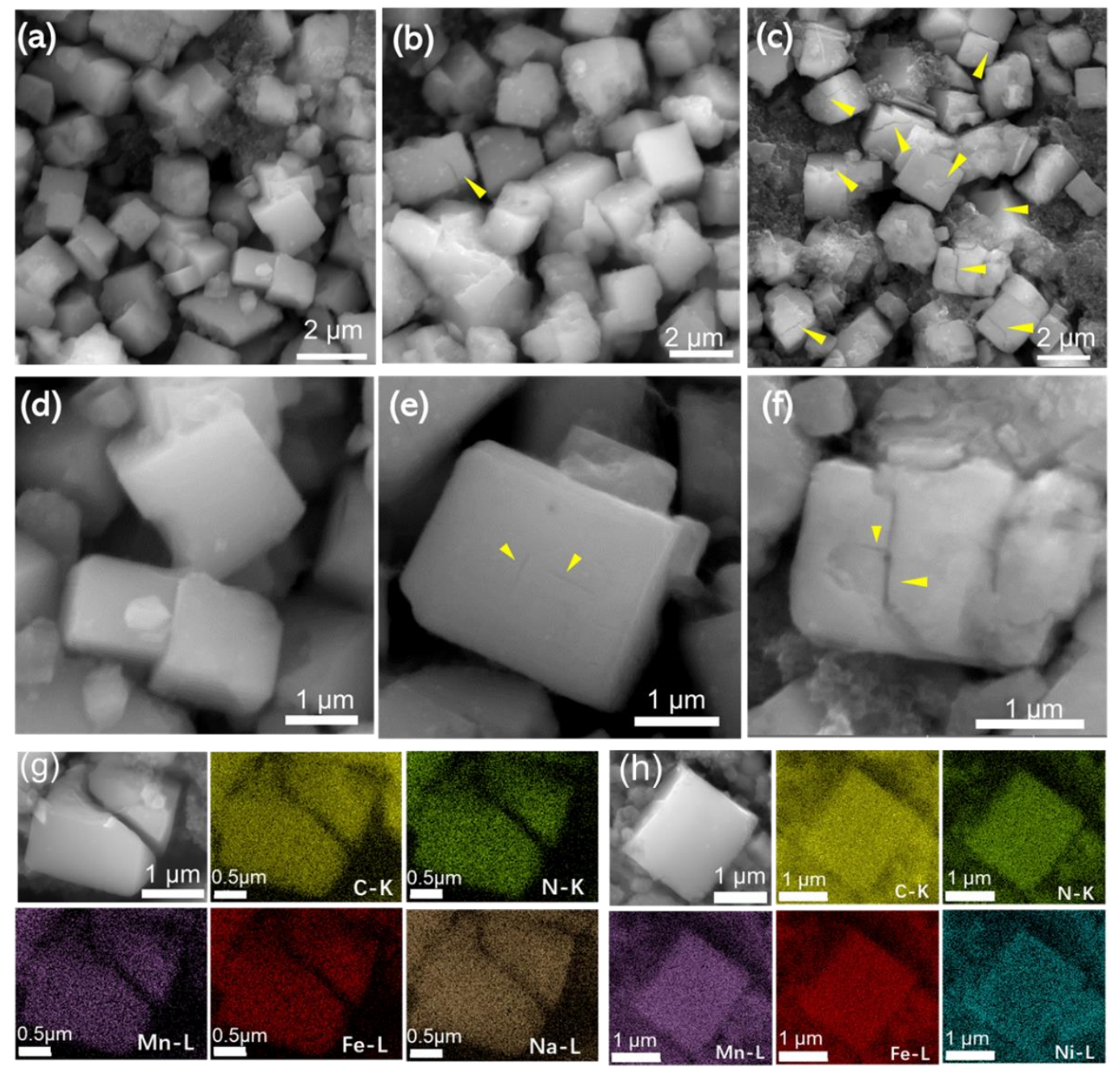

Figure 3 (a-c) Low magnification SEM images of MnHCF materials after (a) 10, (b) 20 and (c) 50 cycles. (d-f) High magnification SEM images of MnHCF materials after (d) 10, (e) 20 and (f) 50 cycles. (g-h) SEM images and element mapping of (g) MnHCF and (h) g-(Nio.1 Mno.9) HCF after 100 cycles. 
Scanning electron microscopy (SEM) was performed to determine the initiation and propagation of fracture in the PBA cathodes upon cycling. Figure S13 shows the morphology of active particles for the MnHCF (Figure S13a) and g-(Nio.1 $\left.\mathrm{Mn}_{0.9}\right) \mathrm{HCF}$ (Figure S13b) cathodes before cycling. As shown in Figure 3, the MnHCF particles retained their cubic shape and size upon cycling, however, the morphology of their surface changed and became rougher/coarser. Such morphological changes can be attributed into the dissolution of $\mathrm{Mn}^{2+}$ into the organic electrolyte, ${ }^{29}$ leading to corrosion of the surface. MnHCF active particles exhibited no obvious signs of fracture after 10 cycles, however small-scale crack initiation and propagation was observed from 20 cycles (Figure $3 b$ and e). After 50 cycles (Figure 3c), fracture was observed in almost every particle. The cracks appeared on the face center of each particle. The crack width after 100 cycles (Figure3g) was measured to be $\sim 100 \mathrm{~nm}$. These experimental observations can interpret the capacity decay that is seen in Figure $2 \mathrm{~b}$ after 100 cycles. It is expected that the structural changes in the form of phase transitions and/or volume expansions during sodiation can induce strain/stress in the active particles, resulting in mechanical damage and capacity fade. Moreover, comparing the XRD patterns at different states of charge (Figure S14a) showed that splitting peaks at $\sim 23.7^{\circ}$ and $37.9^{\circ}$ in the pristine electrode are merged into sharp single peaks at the charged state, due to the phase transformation from monoclinic to cubic. The peaks of the charged electrode shifted to a slightly lower angle, suggesting the expansion of the lattice during the $\mathrm{Na}^{+}$extraction process. All diffraction peaks returned to their pristine state after complete sodiation, illustrating that the phase transformation was reversible during charge/discharge, however, the electrode suffered a $\sim 8.5 \%$ volume change during this process (as determined by refining the XRD peaking with the Fullprof software), which is consistent with previous studies. ${ }^{26}$ These structural changes would contribute to the fracture of the active particles. Such fracture 
disrupts the electronic conductivity and ionic diffusion in the electrode, moreover corrosion causes parasitic side reactions on the newly formed surfaces, thus leading to a continuous capacity fade. In contrast, the gradient material $\mathrm{g}-\left(\mathrm{Ni}_{0.1} \mathrm{Mn}_{0.9}\right) \mathrm{HCF}$ cathode retained its structural integrity during cycling, as no obvious cracking was observed after 100 cycles (Figure 3h).

(a)

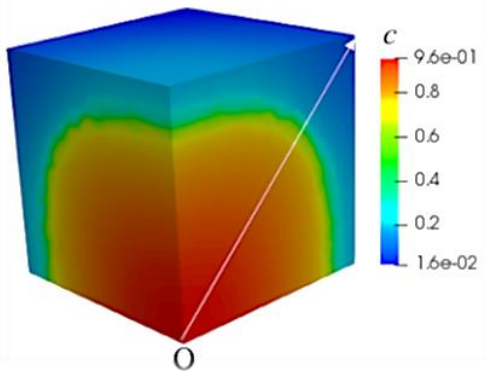

(d)

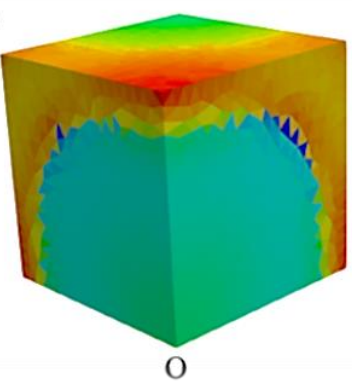

(g)

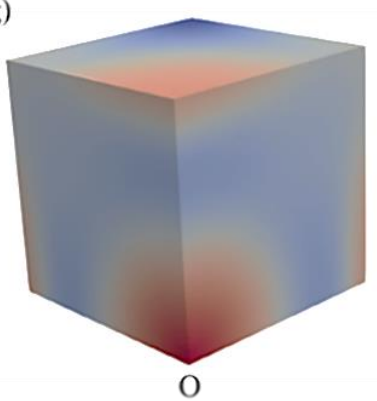

(b)

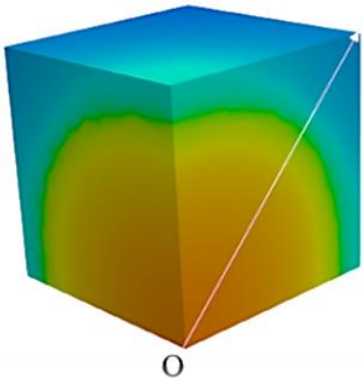

(e)

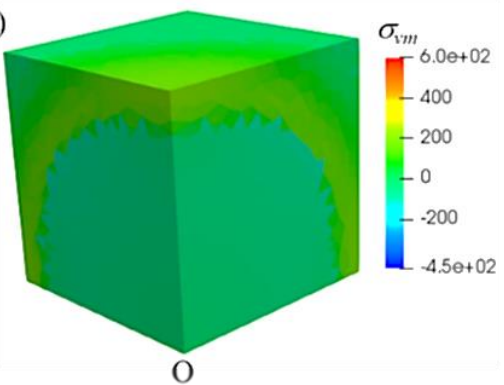

(h)
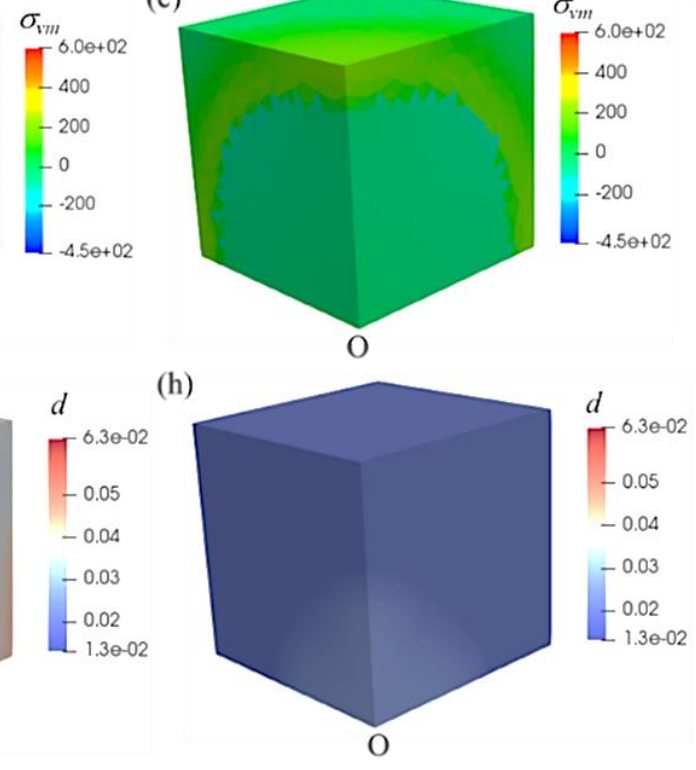
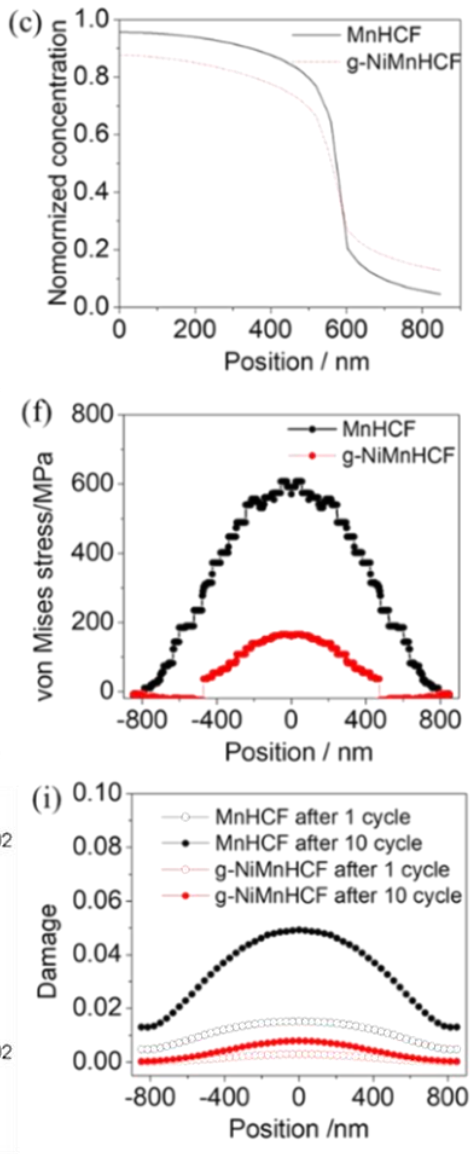

Figure 4. Chemomechanical simulation results showing damage evolution and stress generation in MnHCF and g-NiMnHCF during electrochemical cycling. (a)-(b) Concentration distribution in one-eighth unit cell at $50 \%$ state of charge (SOC) for (a) MnHCF and (b) g-NiMnHCF. (c) Concentration profiles from the center of the particle to the edge center of the top surface (along white arrows in a and b). (d)-(f) Modulated von Mises stress $\left(\sigma_{\mathrm{vm}}\right)$ distribution in MnHCF (d) and 
g-NiMnHCF (e) during cycling. (f) Comparison of modulated von Mises stress profiles along the diagonal line on the top surface of MnHCF and g-NiMnHCF. (g)-(h) Damage distribution of MnHCF (g) and g-NiMnHCF (h) materials after 10 cycles respectively. (i) Comparison of damage profiles along the diagonal line on the top surface of MnHCF and g-NiMnHCF after 10 cycles.

To gain a thorough understanding of crack formation, finite element simulations were performed to model diffusion-induced stresses and damage in active particles during repeated electrochemical cycles using the model presented in Ref $\left[{ }^{35}\right]$. Considering symmetry, only oneeighth of the cubic particle was modelled. As shown in Figure S17a, the letter "O" marks the center of the particle. Two different compositions MnHCF and g-NiMnHCF were considered. Since both materials undergo a two-phase reaction mechanism (monoclinic to cubic phase transition) during sodiation/desodiation, at each intermediate state the active particle was treated as a core-shell-like cubic structure, where the core region was the pristine part and the shell region was the de-sodiated region. Contour plots (Figure 4a and b) of the normalized $\mathrm{Na}^{+}$concentration $\left(C_{\mathrm{Na}}^{+}\right)$obtained by the concentration-dependent diffusivity equation (as shown in Eq-S1) show a sharp phase reaction and steep distribution of $\mathrm{C}_{\mathrm{Na}}{ }^{+}$, which would cause an abrupt change of stresses in the two-phase regions; where the core region is under compressive (negative) stress while the shell is under tensile (positive) stress during desodiation (as shown Figure $4 \mathrm{~d}$ and e). Therefore, there is a jump of the hydrostatic stress $\left(\sigma_{\mathrm{h}}=\operatorname{tr}(\boldsymbol{\sigma}) / 3\right)$ at the de-sodiation reaction front. Figure $4 \mathrm{c}$ compares the diagonal distributions of $\mathrm{CNa}_{\mathrm{Na}}{ }^{+}$in MnHCF and g- NiMnHCF. The profile for $\mathrm{CNa}^{+}$is less steep for g-NiMnHCF than for MnHCF due to the faster diffusion of $\mathrm{Na}^{+}$in g-NiMnHCF. It should also be noted that $\mathrm{g}-\mathrm{NiMnHCF}$ has a much lower volume expansion (0.29\%) than that of MnHCF (8.5\%). Both factors lead to a significantly lower Von Mises stress than in MnHCF. 
The von Mises stress $\left(\sigma_{\mathrm{v}}\right)$ distribution was investigated since it's the main factor contributing to plastic deformation and fracture. Figure 4(d-e) depicts the contour plots of the modulated von Mises stress $\left(\sigma_{\mathrm{vm}}=\operatorname{sign}\left(\sigma_{\mathrm{h}}\right) \times \sigma_{\mathrm{v}}\right.$ where $\operatorname{sign}\left(\sigma_{\mathrm{h}}\right)$ represents the sign function of $\sigma_{\mathrm{h}}$ and its value is 1 when $\sigma_{\mathrm{h}}>0$ and -1 when $\sigma_{\mathrm{h}}<0$ ) for MnHCF and g-NiMnHCF at a $50 \%$ state of charge (SOC). The maximum value for $\sigma_{\mathrm{v}}$ is located near the core(pristine)-shell(sodiated) interface. Figure $4 \mathrm{f}$ compares the $\sigma_{\mathrm{vm}}$ distributions along the diagonal direction on the surfaces-of the particle. The maximum $\sigma_{\mathrm{v}}$ is also observed at the center of the cubic particles, however, there is an appreciable difference in the magnitude of the observed stress in MnHCF (607 MPa) and g-NiMnHCF (165 MPa). The maximum $\sigma_{v}$ in MnHCF is nearly 4 times of that in g-NiMnHCF. It should also be noted that for g-NiMnHCF, the region under tension is of very limited volume contrary to what occurs in MnHCF (Figure 4f). Almost the entire external surface of MnHCF is under tension whereas in g-NiMnHCF only the region near the vertex is in compression.

The damage evolution is further simulated to understand the impact of different compositions on the mechanical degradation of the particles. Since no pre-existing cracks or flaws were considered in the simulation, the damage profiles are similar during initial cycling, for both homogeneous and gradient cathodes, as shown in Figure S18 and Figure 4g-h, which demonstrate the damage profiles of MnHCF and g-NiMnHCF after the $1^{\text {st }}$ and $10^{\text {th }}$ cycle, respectively. A scalar phase-field variable $d$ ranging from 0 to 1 ( $d=0$ for unbroken/intact state, and $d=1$ for fully broken damaged state) is defined. Damage in MnHCF was localized near the center of the external surfaces as well as near the center of the particles, while damage in g-NiMnHCF particles, was confined to the center of the cell (Figure 4h). Figure S18 shows that the maximum damage increased upon cycling for both MnHCF and g-NiMnHCF, however, the damage values at the particle center and surface center of MnHCF increased to $6.35 \%$ and $4.83 \%$ after 10 cycles, which 
is much higher when compared with g-NiMnHCF (1.96\% and 0.79\%, respectively). g-NiMnHCF exhibited alleviation of accumulated damage in the vicinity of the face center. Figure $4 \mathrm{i}$ shows the damage distribution of MnHCF and g-NiMnHCF along the diagonal line on the top surface after 1 and 10 cycles, respectively. Similar damage profiles were observed, however, the magnitudes were significantly different; the maximum damage values for MnHCF being $1.52 \%$ and $4.92 \%$ and for g-NiMnHCF being $0.31 \%$ and $0.80 \%$ after 1 and 10 cycles, respectively. Both homogenous and concentration-gradient particles demonstrate about a 3-fold increase in maximum damage over the $1^{\text {st }}$ and $10^{\text {th }}$ cycle, even though for the g-NiMnHCF it is negligible. Fracture is likely to occur in regions showing increased damage upon cycling, and therefore if the simulation for the homogeneous materials was run over 20 cycles, cracks would nucleate as in the experimental images. However, due to computational costs simulations were stopped after 10 cycles. In Figure 4 it is seen that the predicted damage value is significantly low in g-NiMnHCF particles, and no cracks were anticipated. Therefore, g-NiMnHCF has a much better mechanical performance than MnHCF.

(a)
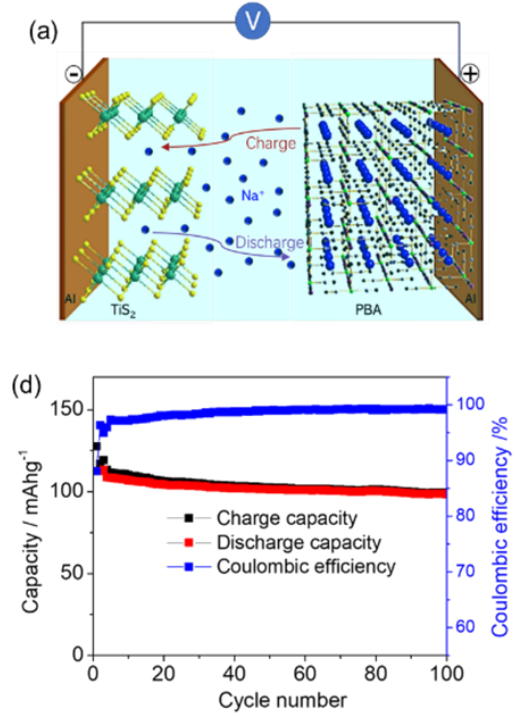

(b)
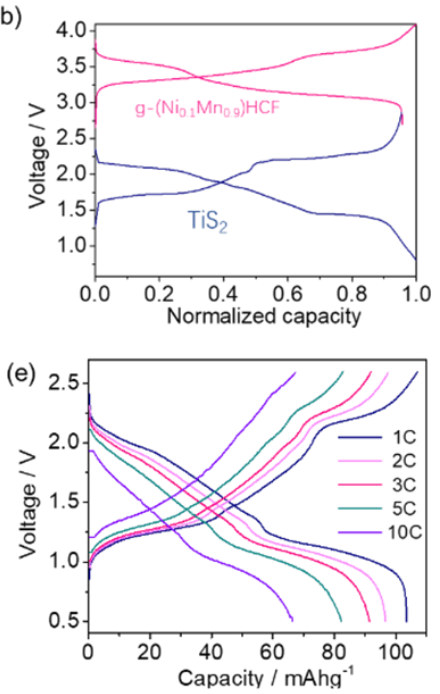
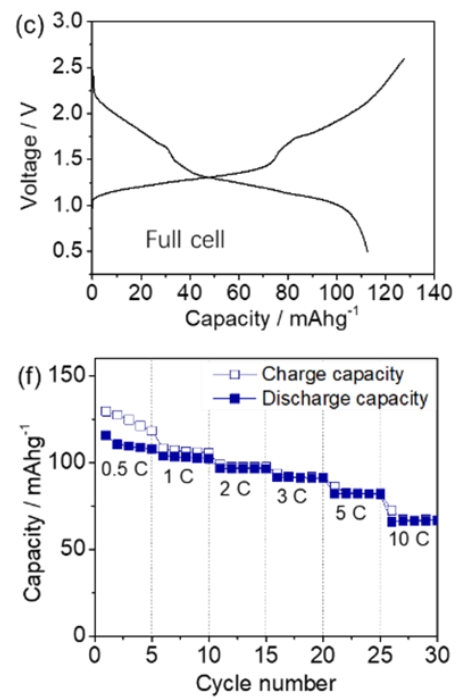
Figure. 5 (a) Schematic mechanism of full cell that using g-NiMnHCF as cathode and $\mathrm{TiS}_{2}$ as anode. (b) Charge/discharge profiles of g-Nio.1 $\mathrm{Mn}_{0.9} \mathrm{HCF}$ and $\mathrm{TiS}_{2}$ in half cell. (c) The first charge/discharge curves of the full cell using g-Ni $\mathrm{Ni}_{0.1} \mathrm{Mn}_{0.9} \mathrm{HCF}$ as cathode and $\mathrm{TiS}_{2}$ as anode. (d) Cycling performance of the full cell at $0.5 \mathrm{C}$. (e) Charge/discharge curve and rate capability of the full cell at different C-rate. (f)The capacity was calculated by the cathode mass.

Sodium metal is not an ideal anode for commercial batteries due to its high reactivity with the electrolyte and dendrite formation ${ }^{36}$, which results in safety issues. Carbon-based materials such as hard carbon and graphite are commonly used as anodes for Na-ion full cells. However, the potential plateau of hard carbon is close to the plating potential of $\mathrm{Na}$, leading to the formation of $\mathrm{Na}$ dendrites during the charge process. ${ }^{37-38}$ In testing the present gradient PBAs in a full cell, graphitic anodes were considered first, which cycle only in glyme electrolyte. In Figure S15a and $\mathrm{b}$ it is seen that a capacity of $125 \mathrm{mAh} \mathrm{g}^{-1}$ and a low initial Coulombic efficiency (C.E.) of $70 \%$ were obtained after the first cycle. In Figure $\mathrm{S} 15 \mathrm{c}$ it is seen that although the g$\left(\mathrm{Ni}_{0.1} \mathrm{Mn}_{0.9}\right) \mathrm{HCF} /$ graphite full cell displayed a stable discharge capacity within 100 cycles, it delivered a low C.E. of $50 \%$. Therefore, activation of the graphite anode is required before coupling with the cathode to assemble a full cell. Our previous research demonstrated that $\mathrm{TiS}_{2} / \mathrm{Na}$ half-cells presented superior electrochemical performance in carbonate-based electrolyte. Herein, therefore a layered-type $\mathrm{TiS}_{2}$ with particle size of $\sim 5 \mu \mathrm{m}$ (Figure $\mathrm{S} 16 \mathrm{~b}$ ) was chosen as the anode. The strong (001) diffraction peak (Figure S16a) implied a highly preferred orientation along the $c$-axis direction and good S-Ti-S layer stacks. Using $\mathrm{TiS}_{2}$ in a half Na-ion cell allowed to obtain a high reversible capacity of $200 \mathrm{mAh} \mathrm{g}^{-1}$ at $0.5 \mathrm{C}$, initial Coulombic efficiency (95\%), cycling stability and rate capability ( $157 \mathrm{mAh} \mathrm{g}^{-1}$ at $5 \mathrm{C}, 122 \mathrm{mAh} \mathrm{g}^{-1}$ at $10 \mathrm{C}$ ), as seen in Figure S16c-d. 
A full cell, as illustrated in Figure 5a, was therefore assembled by using g-( $\left.\mathrm{Ni}_{0.1} \mathrm{Mn}_{0.9}\right) \mathrm{HCF}$ as the cathode, $\mathrm{TiS}_{2}$ as the anode and $1 \mathrm{M} \mathrm{NaPF}_{6}$ in $\mathrm{EC} / \mathrm{DMC}$ with $5 \% \mathrm{FEC}$ as the electrolyte. Figure $5 \mathrm{~b}$ shows charge/discharge profiles of voltage vs. normalized capacity for g-( $\left.\mathrm{Ni}_{0.1} \mathrm{Mn}_{0.9}\right) \mathrm{HCF}$ and $\mathrm{TiS}_{2}$ electrodes. The voltage difference between the two electrodes determines the working voltage of the full cell. As shown in Figure 5c, the full cell presents two potential profiles at $\sim 1.2 \mathrm{~V}$ and $\sim 2.1 \mathrm{~V}$. The initial charge and discharge capacities were $127 \mathrm{~mA} \mathrm{~h} \mathrm{~g}^{-1}$ and $112 \mathrm{~mA} \mathrm{~h} \mathrm{~g}^{-1}$ at $0.5 \mathrm{C}$ in the potential range of $0.5-2.6 \mathrm{~V}$, exhibiting a high initial C.E. of $88.1 \%$. High C.E. benefits from the highly reversible nature of both the cathode and anode materials. The cycling stability of the full cell was examined at $1 \mathrm{C}$. As shown in Figure 5d, the reversible capacity of the cathode in the full cell reached $110 \mathrm{~mA} \mathrm{~h} \mathrm{~g}^{-1}$ and a capacity retention of $87.5 \%$ was observed over 100 cycles. Figure 5(e-f) shows that the capacity decreased slightly as the rate increased from $0.5 \mathrm{C}$ to $10 \mathrm{C}$. At $5 \mathrm{C}$ and $10 \mathrm{C}$, it still achieved a capacity of $88 \mathrm{mAh} \mathrm{g}^{-1}$ and $70 \mathrm{mAh} \mathrm{g}^{-1}$, implying excellent rate capability. Comparing with the performance of full cells reported in previous studies (Table S3), our results show a superior rate capability, initial C.E and stability, which indicates a great advance over the state-of-the-art of sodium-ion batteries. The output voltage of the full cell is lower than the organic cell using carbon and alloying anode, but it is in the stable potential window of the aqueous electrolyte, making it feasible to run in an aqueous electrolyte. The aqueous SIBs based on these materials will be studied in-depth in further work.

In conclusion, concentration-gradient materials g-NiMnHCF were successfully synthesized via a facile co-precipitation process, resulting in a Ni rich shell and $\mathrm{Mn}$ core. The expansion of NiHCF upon sodiation is less than $1 \%$, whereas that of MnHCF is $8.5 \%$, hence this gradient microstructure allows to buffer the core volume changes. The as-obtained gradient microstructure cathodes exhibited outstanding cycling stability and rate capability, when compared with the 
homogenous MnHCF cathodes. SEM images revealed that after twenty cycles cracks initiated and propagated at the center of the MnHCF particles, but no damage occurred in the g-NiMnHCF. The superior electrochemical performance of g-NiMnHCF could therefore be attributed to its stable structure and fast ionic diffusivity, which reduce the mechanical degradation induced by diffusion at the reaction front during charge/discharge. The experimental data were interpreted with phase field modeling which showed that g-NiMnHCF experiences lower von Mises stresses and hydrostatic stress levels and negligible damage, while MnHCF with a uniform composition undergoes higher stresses, and the damage tends to localize at regions close to the particle center and face centers. The maximum damage for MnHCF is more than 3 times as that for g-NiMnHCF. As a result, g-NiMnHCF shows better damage tolerance and its mechanical degradation due to excessive stresses can be effectively retarded. In concluding, a full cell using $\mathrm{TiS}_{2}$ as the anode and g-NiMnHCF as the cathode was shown to have an outstanding initial Coulombic efficiency, capacity retention and rate capability, demonstrating potential practical applications in energy storage. Therefore, designing gradient composition materials is an effective approach to improve the stability of PBA cathodes. We also believe that this approach can be reasonably extended to other electrode materials to solve the mechanical degradation in LIBs and SIBs.

\section{Supporting Information.}

The Supporting Information is available free of charge on the ACS Publications website at DOI:xxxx.

Experimental details of preparation, characterizations and simulations. Additional figures and tables showing TGA, XRD, ICP, SEM, and simulation results.

\section{Notes}


The authors declare no competing financial interest.

\section{Acknowledgements}

The authors are grateful to the National Science Foundation for supporting this work through the CMMI grant (CMMI-1762602).

\section{References}

1. Goodenough, J. B.; Park, K.-S., The Li-Ion Rechargeable Battery: A Perspective. J. Am. Chem. Soc. 2013, 135, 1167-1176.

2. Scrosati, B.; Hassoun, J.; Sun, Y. K., Lithium-ion batteries. A look into the future.

Energy Environ. Sci. 2011, 4, 3287-3295.

3. Zuo, Y. X.; Li, B. A.; Jiang, N.; Chu, W. S.; Zhang, H.; Zou, R. Q.; Xia, D. G., A HighCapacity O2-Type Li-Rich Cathode Material with a Single-Layer $\mathrm{Li}_{2} \mathrm{MnO}_{3}$ Superstructure. $A d v$. Mater. 2018, 30,1707255.

4. Hwang, J. Y.; Myung, S. T.; Sun, Y. K., Sodium-ion Batteries: Present and Future. Chem. Soc. Rev. 2017, 46, 3529-3614.

5. Hu, Y. S.; Komaba, S.; Forsyth, M.; Johnson, C.; Rojo, T., A New Emerging Technology: Na-Ion Batteries. Small Methods 2019, 3, 1900184.

6. Ebner, M.; Marone, F.; Stampanoni, M.; Wood, V., Visualization and Quantification of Electrochemical and Mechanical Degradation in Li Ion Batteries. Science 2013, 342, 716-720.

7. Aifantis, K. E.; Huang, T.; Hackney, S. A.; Sarakonsri, T.; Yu, A. S., Capacity fade in Sn-C nanopowder anodes due to fracture. J. Power Sources 2012, 197, 246-252.

8. Aifantis, K. E.; Hackney, S. A., Mechanical Stability for Nanostructured Sn- and SiBased Anodes. J. Power Sources 2011, 196, 2122-2127. 
9. Aifantis, K. E.; Dempsey, J. P., Stable Crack Growth in Nanostructured Li-batteries. J. Power Sources 2005, 143, 203-211.

10. Xu, J. G.; Deshpande, R. D.; Pan, J.; Cheng, Y. T.; Battaglia, V. S., Electrode Side Reactions, Capacity Loss and Mechanical Degradation in Lithium-Ion Batteries. J. Electrochem. Soc. 2015, 162, A2026-A2035.

11. Aifantis, K. E.; Haycock, M.; Sanders, P.; Hackney, S. A., Fracture of Nanostructured Sn/C Anodes during Li-insertion. Mat Sci Eng a-Struct 2011, 529, 55-61.

12. McGrogan, F. P.; Raja, S. N.; Chiang, Y. M.; Van Vliet, K. J., Electrochemomechanical Fatigue: Decoupling Mechanisms of Fracture- Induced Performance Degradation in $\mathrm{Lix}_{\mathrm{X}} \mathrm{Mn}_{2} \mathrm{O}_{4}$. J. Electrochem. Soc. 2018, 165, A2458-A2466.

13. Qi, Y.; Xu, Q. C.; Van der Ven, A., Chemically Induced Crack Instability When Electrodes Fracture. J. Electrochem. Soc. 2012, 159, A1838-A1843.

14. Hao, X. G.; Lin, X. K.; Lu, W.; Bartlett, B. M., Oxygen Vacancies Lead to Loss of Domain Order, Particle Fracture, and Rapid Capacity Fade in Lithium Manganospinel $\left(\mathrm{LiMn}_{2} \mathrm{O}_{4}\right)$ Batteries. ACS Appl. Mater. Interfaces 2014, 6, 10849-10857.

15. Qu, M.; Woodford, W. H.; Maloney, J. M.; Carter, W. C.; Chiang, Y. M.; Van Vliet, K. J., Nanomechanical Quantification of Elastic, Plastic, and Fracture Properties of $\mathrm{LiCoO}_{2} . A d v$. Energy Mater. 2012, 2, 940-944.

16. Yu, Y. S.; Kim, C.; Shapiro, D. A.; Farmand, M.; Qian, D.; Tyliszczak, T.; Kilcoyne, A. L. D.; Celestre, R.; Marchesini, S.; Joseph, J.; Denes, P.; Warwick, T.; Strobridge, F. C.; Grey, C. P.; Padmore, H.; Meng, Y. S.; Kostecki, R.; Cabana, J., Dependence on Crystal Size of the Nanoscale Chemical Phase Distribution and Fracture in $\mathrm{Li}_{\mathrm{x}} \mathrm{FePO}_{4}$. Nano Lett. 2015, 15, 42824288. 
17. Yan, P. F.; Zheng, J. M.; Gu, M.; Xiao, J.; Zhang, J. G.; Wang, C. M., Intragranular Cracking as a Critical Barrier for High-Voltage Usage of Layer-Structured Cathode for LithiumIon Batteries. Nat. Commun. 2017, 8, 14101.

18. Xu, B.; Meng, S., Factors Affecting Li Mobility in Spinel $\mathrm{LiMn}_{2} \mathrm{O}_{4}$-A First-Principles Study by GGA and GGA Plus U methods. J. Power Sources 2010, 195, 4971-4976.

19. Wang, D. Y.; Wu, X. D.; Wang, Z. X.; Chen, L. Q., Cracking Causing Cyclic Instability of $\mathrm{LiFePO}_{4}$ Cathode Material. J. Power Sources 2005, 140, 125-128.

20. Wang, J. W.; Liu, X. H.; Mao, S. X.; Huang, J. Y., Microstructural Evolution of Tin Nanoparticles during In Situ Sodium Insertion and Extraction. Nano Lett. 2012, 12, 5897-5902.

21. Gu, M.; Kushima, A.; Shao, Y. Y.; Zhang, J. G.; Liu, J.; Browning, N. D.; Li, J.; Wang, C. M., Probing the Failure Mechanism of $\mathrm{SnO}_{2}$ Nanowires for Sodium-Ion Batteries. Nano Lett. 2013, 13, 5203-5211.

22. You, Y.; Wu, X. L.; Yin, Y. X.; Guo, Y. G., High-Quality Prussian Blue Crystals as Superior Cathode Materials for Room-Temperature Sodium-Ion Batteries. Energy Environ. Sci. 2014, 7, 1643-1647.

23. Wang, L.; Lu, Y. H.; Liu, J.; Xu, M. W.; Cheng, J. G.; Zhang, D. W.; Goodenough, J. B., A Superior Low-Cost Cathode for a Na-Ion Battery. Angew Chem Int Edit 2013, 52, 1964-1967. 24. Lu, Y. H.; Wang, L.; Cheng, J. G.; Goodenough, J. B., Prussian Blue: a New Framework of Electrode Materials for Sodium Batteries. Chem. Commun. 2012, 48, 6544-6546.

25. Xiao, P. H.; Song, J.; Wang, L.; Goodenough, J. B.; Henkelman, G., Theoretical Study of the Structural Evolution of a $\mathrm{Na}_{2} \mathrm{FeMn}(\mathrm{CN})_{6}$ Cathode upon $\mathrm{Na}$ Intercalation. Chem. Mater. 2015, 27, 3763-3768. 
26. Song, J.; Wang, L.; Lu, Y. H.; Liu, J.; Guo, B. K.; Xiao, P. H.; Lee, J. J.; Yang, X. Q.; Henkelman, G.; Goodenough, J. B., Removal of Interstitial $\mathrm{H}_{2} \mathrm{O}$ in Hexacyanometallates for a Superior Cathode of a Sodium-Ion Battery. J. Am. Chem. Soc. 2015, 137, 2658-2664.

27. Pan, H. L.; Hu, Y. S.; Chen, L. Q., Room-Temperature Stationary Sodium-Ion Batteries For Large-Scale Electric Energy Storage. Energy Environ. Sci. 2013, 6, 2338-2360.

28. Matsuda, T.; Takachi, M.; Moritomo, Y., A Sodium Manganese Ferrocyanide Thin Film For Na-Ion Batteries. Chem. Commun. 2013, 49, 2750-2752.

29. Gao, H. C.; Xin, S.; Xue, L. G.; Goodenough, J. B., Stabilizing a High-Energy-Density Rechargeable Sodium Battery with a Solid Electrolyte. Chem-Us 2018, 4, 833-844.

30. Yang, D. Z.; Xu, J.; Liao, X. Z.; He, Y. S.; Liu, H. M.; Ma, Z. F., Structure Optimization of Prussian Blue Analogue Cathode Materials for Advanced Sodium Ion Batteries. Chem.

Commun. 2014, 50, 13377-13380.

31. Moritomo, Y.; Urase, S.; Shibata, T., Enhanced Battery Performance in Manganese Hexacyanoferrate by Partial Substitution. Electrochim. Acta 2016, 210, 963-969.

32. Moritomo, Y.; Wakaume, K.; Takachi, M.; Zhu, X. H.; Kamioka, H., Li ${ }^{+}$Intercalation of Manganese Ferrocyanide as Investigated by In situ Valence-Differential Absorption Spectroscopy. J. Phys. Soc. Jpn. 2013, 82,094710.

33. Tang, K.; Yu, X. Q.; Sun, J. P.; Li, H.; Huang, X. J., Kinetic analysis on LiFePO4 thin films by CV, GITT, and EIS. Electrochim. Acta 2011, 56, 4869-4875.

34. Rui, X. H.; Ding, N.; Liu, J.; Li, C.; Chen, C. H., Analysis of the Chemical Diffusion Coefficient of Lithium Ions in $\mathrm{Li}_{3} \mathrm{~V}_{2}\left(\mathrm{PO}_{4}\right)_{3}$ Cathode Material. Electrochim. Acta 2010, 55, 23842390. 
35. Rethore, J.; Zheng, H.; Li, H.; Li, J. J.; Aifantis, K. E., A Multiphysics Model that can Capture Crack Patterns in Si Thin Films Based on Their Microstructure. J. Power Sources 2018, 400, 383-391.

36. Zhao, Y.; Adair, K. R.; Sun, X. L., Recent Developments and Insights into the Understanding of Na Metal Anodes for Na-Metal Batteries. Energy Environ. Sci. 2018, 11, 26732695.

37. Liu, T.; Zhang, Y.; Jiang, Z.; Zeng, X.; Ji, J.; Li, Z.; Gao, X.; Sun, M.; Lin, Z.; Ling, M.; Zheng, J.; Liang, C., Exploring Competitive Features of Stationary Sodium Ion Batteries for Electrochemical Energy Storage. Energy Environ. Sci. 2019, 12, 1512-1533.

38. Jache, B.; Adelhelm, P., Use of Graphite as a Highly Reversible Electrode with Superior Cycle Life for Sodium-Ion Batteries by Making Use of Co-Intercalation Phenomena. Angew Chem Int Edit 2014, 53, 10169-10173. 